\title{
ДОПУСТИМЕ ОЦІНЮВАННЯ МНОЖИНИ ПАРАМЕТРІВ СТАТИЧНОЇ СИСТЕМИ В КЛАСІ БАГАТОМІРНИХ ЕЛІПСОЇДІВ
}

\author{
М. Дивак
}

Тернопільська академія народного господарства

Резюме: Розглянуто методи побудови допустимих еліпсоїдальних оцінок області працездатності статичної системи. Показано умови існування області допусків, коли статична система описується інтервальною моделлю і розроблено ітераційний алгоритм, який дозволяє сумістити процедури локалізації множини параметрів моделі і допустимого еліпсоїдального оцінювання. Проведено аналіз задачі допустимого оцінювання параметрів лінеаризованої інтервальної моделі в умовах ідентифікації базових функцій, який дозволив виробити підходи до вибору конфігурації допустимої еліпсоїдальної оцінки.

Ключові слова: допустимі еліпсоїдальні оцінки, область працездатності статичної системи, інтервальна модель, інтервальний аналіз.

\section{ПОСТАНОВКА ЗАДАЧІ}

Точність статичної системи в значній мірі визначається точністю компонент, з яких вона складається. Кожна $i$ - та вихідна характеристика системи $є$ функцією параметрів компонент, значення яких утворюють вектор $\vec{b}=\left(b_{1}, \ldots, b_{j}, \ldots, b_{m}\right)^{T}$. Традиційно при проектуванні системи знаходять вектор номінальних значень параметрів іiї компонент $\vec{b}_{o}$, який забезпечує номінальні значення характеристик $y_{i}\left(\vec{b}_{0}\right)$. В процесі виробництва та експлуатації системи, реальні значення цих характеристик відрізняються від номінальних. При цьому, чим більші відхилення реальних значень від номінальних, тим менша точність системи. Застосувавши до нелінійних, у загальному випадку, характеристик системи $y_{i}\left(\vec{b}_{0}\right)$ лінеаризацію по логарифмічних значеннях параметрів у околі точки $\left(\ln \left(b_{o 1}\right), \ldots, \ln \left(b_{o m}\right)\right)$, вимоги до точності характеристик системи записують у вигляді такої системи двохсторонніх лінійних нерівностей, яку надалі називатимемо інтервальною системою лінійних алгебраїчних рівнянь (ІСЛАР) [1]:

$y_{i}^{-} \leq y_{i 0}+\left.\sum_{j=1}^{m} \frac{\partial y_{i}(\vec{b})}{\partial \ln b_{j}}\right|_{\vec{b}=\vec{b}_{0 j}} \cdot \delta b_{j} \leq y_{i}^{+}, i=1, \ldots, N$, де $y_{i}^{-}, y_{i}^{+}-$нижня та верхня межі допустимихзначень вихідних характеристик системи. Перейдемо у системі інтервальних рівнянь (1) до допусків для $i$ - тої характеристики $\delta y_{i}^{-}=y_{i}^{-}-y_{i 0}, \delta y_{i}^{+}=y_{i}^{+}-y_{i 0}$. Тоді отримана ІСЛАР матиме такий вигляд:

$$
\delta \vec{Y}^{-} \leq S \cdot \delta \vec{b} \leq \delta \vec{Y}^{+},
$$

де

$$
\delta \vec{Y}^{-}=\left\{\delta y_{i}^{-}, i=1, \ldots, N\right\}, \delta \vec{Y}^{+}=\left\{\delta y_{i}^{+}, i=1, \ldots, N\right\}
$$
вектори, складені із верхніх та нижніх меж інтервалів $\left[\delta y_{i}^{-}, \delta y_{i}^{+}\right]$відхилень вихідної характеристики від номінального значення, відповідно; $S=\left\{S_{i j}=\left.b_{j} \cdot \frac{\partial y_{i}(\vec{b})}{\partial\left(b_{j}\right)}\right|_{\vec{b}_{0}}\right.$, $i=\overline{1, N}, j=\overline{1, m}\}$ - матриця чутливостей $S_{i j} i$ тої характеристики до зміни значення $j$ - того параметра системи; $\delta \vec{b}$-вектор з компонентами $\delta b_{j}=\ln \left(b_{j}\right)-\ln \left(b_{o j}\right)$.

Розв'язком отриманої системи інтервальних рівнянь в просторі параметрів $\vec{b} \in R^{m} \in$ область працездатності статичної системи, яка одночасно $є$ допустимою областю $\widetilde{\Omega}$. Властивості цієї області розглянуті у праці [2]. Зокрема, у просторі параметрів вона $є$ опуклим многогранником з вершинами 


$$
\delta \vec{b}_{s}=S^{-1} \cdot \delta \vec{Y}_{s}, \quad s=1, \ldots, 2^{m}
$$

де $\delta \vec{Y}_{s}$ - вектор, складений із комбінацій нижніх та верхніх меж інтервалів $\left[\delta y_{i}^{-}, \delta y_{i}^{+}\right]$ відхилень вихідної характеристики від номінального значення. Будь-які значення параметрів $\vec{b}$, вибрані із множини $\widetilde{\Omega}$, забезпечують допустимі значення усіх виходів $y_{i}$.

Оскільки кількість характеристик статичної системи, переважно, є меншою від кількості іiі параметрів, то задавши додаткові обмеження $\delta b_{j}^{-} \leq \delta b_{j} \leq \delta b_{j}^{+}$на значення частини параметрів, прийдемо до випадку $N=m$. Тоді матриця чутливостей $S$ у системі (2) є квадратною $(m \times m)$, а область працездатності у просторі параметрів $\epsilon$ гіперпаралелепіпедом $\widetilde{\Omega}_{m}$. Припустимо також, що $\operatorname{rang}(S)=m$.

При розв'язуванні задач аналізу та синтезу допусків на параметри статичної системи, традиційно застосовують інтервальні методи допустимого оцінювання, коли у область працездатності $\widetilde{\Omega}_{m}$ вписують прямокутні паралелепіпеди з гранями, паралельними осям координат [3]. Очевидно, що при цьому не можливо досягнути значного покриття області працездатності, особливо у випадку іiї сильної “витягнутості". Тому для оцінювання розв'язків системи (2) все частіше застосовують методи допустимого оцінювання в класі багатомірних еліпсоїдів [4]. Подібна задача розглянута у праці [4], де отримана оптимальна еліпсоїдальна оцінка на основі такої теореми: “Для $N=m$ у многогранник $\widetilde{\Omega}_{m}$ можна вписати $m$ - вимірний еліпсоїд

$Q_{m}^{-}=\left\{\vec{b} \in R^{m} \mid(\overrightarrow{\mathscr{B}}-\overrightarrow{\vec{b}})^{T} \cdot S^{T} \cdot \widetilde{E}^{-2} \cdot S \cdot(\vec{\not}-\overrightarrow{\bar{b}}) \leq 1\right\}$,

що дотикається до центрів усіх граней і 3 центром ваги $\delta \overrightarrow{\bar{b}}=S^{-1} \cdot \delta \overrightarrow{\bar{Y}}$ ”.

У виразі (5) $\widetilde{E}$ - діагональна матриця допусків $\widetilde{\Delta}_{i}=0,5 \cdot\left(\delta y_{i}^{+}-\delta y_{i}^{-}\right), i=1, \ldots, m$ відхилень вихідних характеристик об’єкта. Вектор $\delta \overrightarrow{\bar{Y}}$ має такий вигляд:

$$
\delta \overrightarrow{\bar{Y}}=\left(\delta \bar{y}_{1}, \ldots, \delta \bar{y}_{i}, \ldots, \delta \bar{y}_{m}\right)^{T},
$$

$$
\delta \bar{y}_{i}=0,5 \cdot\left(\delta y_{i}^{+}+\delta y_{i}^{-}\right) .
$$

На практиці при аналізі області працездатності замість точної моделі системи часто приходиться використовувати наближені, або спрощені моделі статичної системи, побудовані за результатами експерименту. В цьому випадку запропонований метод [4] допустимого еліпсоїдального оцінювання виявляється непридатним. Метою даної праці є дослідження допустимої оцінки області працездатності $\widetilde{\Omega}_{m}$, отриманої у класі еліпсоїдальних множин для випадку, коли статична система описується інтервальною моделлю [1].

\section{ДОПУСТИМА ЕЛІПСОӤДАЛЬНА ОЦІНКА У ВИПАДКУ МНОЖИННОЇ ДЕНТИФІКАЦІї ПАРАМЕТРІВ ІНТЕРВАЛЬНОÏ МОДЕЛІ}

Нехай в результаті експериментальної множинної ідентифікації отримані інтервальні моделі статичної системи у вигляді множини лінійно - параметричних функцій [1]

$$
f_{i}(\vec{x})=\vec{\varphi}_{i}^{T}(\vec{x}) \cdot \vec{b}, \vec{b} \in \Omega, i=1, \ldots, N,
$$

де $\vec{\varphi}_{i}^{T}(\vec{x})$ - вектор значень базових функцій рівняння $i-$ тої вихідної $y_{i}$ характеристики системи; $\Omega$ - множина векторів оцінок $\vec{b}$ параметрів моделі системи, отримана у результаті множинної ідентифікації.

Позначимо вектор значень базових функцій $\vec{\varphi}_{i}^{T}(\vec{x})$ рівняння $i$ - тої вихідної $y_{i}$ характеристики системи для фіксованого вектора входів $\vec{x}_{i}$ за $\vec{\phi}_{i}^{T}=\left(\phi_{i 1}, \ldots, \phi_{i j}, \ldots, \phi_{i m}\right)$. В загальному випадку значення векторів $\vec{x}_{i}$ для різних виходів можуть відрізнятися між собою. У відповідності з припущеннями, на які спирається метод аналізу інтервальних даних [1], значення кожної $i$ - тої вихідної характеристики для фіксованого вектора входів $\vec{x}_{i}$ гарантовано належить відповідним інтервалам прогнозування $\left[€_{i}\right]=\left[£_{i}^{-} ; £_{i}^{+}\right]$, де межі інтервалів визначаються за такими формулами: 


$$
\begin{aligned}
& \xi_{i}^{-}=\min _{\vec{b}} \sum_{j=1}^{m} \phi_{i j} \cdot b_{j}, \vec{b} \in \Omega, \\
& \xi_{i}^{+}=\max _{\vec{b}} \sum_{j=1}^{m} \phi_{i j} \cdot b_{j}, \vec{b} \in \Omega, \quad i=1, \ldots, N .
\end{aligned}
$$

Розглянемо задачу знаходження допустимої областіпараметрів для отриманих інтервальних моделей 3 інтервалами прогнозування (6). Задаючи інтервали допустимих значень виходів $\left[y_{i}^{-}, y_{i}^{+}\right]$, для фіксованого вектора входів $\vec{x}_{i}$ та 3 врахуванням уведених позначень приходимо до ІСЛАР

$$
\delta \vec{Y}^{-} \leq \widetilde{F} \cdot \delta \vec{b} \leq \delta \vec{Y}^{+}
$$

подібної до ICЛАР (2). Проте у даному випадку матриця чутливості $S$, замінена на матрицю значень базових функцій $\widetilde{F}=\left\{\phi_{i j}, i=\overline{1, N}, j=\overline{1, m}\right\}$, авектори $\delta \vec{Y}^{-}, \delta \vec{Y}^{+}$ складені із верхніх та нижніх меж інтервалів $\left[\delta y_{i}^{-}, \delta y_{i}^{+}\right]$відхилень вихідної характеристики не від номінальних значень, а від граничних значень інтервалу прогнозування $\left[\xi_{i}\right]=\left[\xi_{i}^{-} ; Æ_{i}^{+}\right]$, тобто вони визначаються так:

$$
\delta y_{i}^{-}=y_{i}^{-}-£_{i}^{-}, \delta y_{i}^{+}=y_{i}^{+}-€_{i}^{+}, i=1, \ldots, N .
$$

Відповідно, компоненти вектора $\delta \vec{b}=\left(\delta b_{1}, \ldots, \delta b_{m}\right)^{T}$, отриманого із розв'язку ICЛАР (7), будуть задавати відхилення значень параметрів від граничних точок множини $\Omega$.

Особливістю отриманої ІСЛАР (7) для даного випадку $\epsilon$, що існування іiі розв'язків залежить від ширини інтервалів прогнозування $\left[\S_{i}\right]=\left[\S_{i}^{-} ; £_{i}^{+}\right]$. Зокрема, по цій причині IСЛАР (7) може не мати розв' язків. Тоді це означає, що області допусків $\widetilde{\Omega}$ не існує. Сформулюємо необхідні умови існування області $\widetilde{\Omega}$ у вигляді твердження.

Т в е р д ж е н н я 1. Для існування області допусків необхідно виконання включень

$$
\left[\xi_{i}^{-} ; \aleph_{i}^{+}\right] \subseteq\left[y_{i}^{-}, y_{i}^{+}\right], \forall i=1, \ldots, N
$$

Доведення. Нехай включення (9) не виконується хоча б для одного $i$. Тоді з формули (8) витікає: $\delta y_{i}^{-}>\delta y_{i}^{+}$, що суперечить прийнятому означенню інтервалу і відповідно підтверджує правильність теореми.

Як витікає 3 твердження 1, для існування області допусків $\widetilde{\Omega}$ необхідно забезпечити певну точність прогнозування інтервальних моделей у точках $\vec{x}_{i}$. Звідси стає очевидним, що для отримання області допусків, наприклад, заданого об'єму, раціональним буде суміщення процедур множинної ідентифікації параметрів моделі і допустимого оцінювання.

Застосуємо для цих цілей метод локалізації параметрів моделей 3 виділенням насиченого блоку експерименту, описаний в праці [5].

Допустиму оцінку розв'язку ICЛАР (7) шукатимемо у класі еліпсоїдальних множин (4) максимального об'єму. Спочатку задамо локалізаційну область на $k=0$ ітерації. Для цього покладемо у формулі (8) $£_{i}^{-}=0$, $\mathcal{E}_{i}^{+}=0, \forall i=1, \ldots, N$ і підставимо отримані значення $\delta y_{i}^{-}, \delta y_{i}^{+}$, відповідно, у вектори $\delta \vec{Y}^{-}, \delta \vec{Y}^{+}$ICЛАР (7). Розв'язком цієї системи $\epsilon$ деяка допустима область $\widetilde{\Omega}_{m}$, яка буде використана у локалізаційному методі на $k=0$ ітерації і в цілому буде задавати конфігурацію множини оцінок параметрів інтервальної моделі. Для уточнення оцінок параметрів (зменшення розмірів локалізаційної множини) використовуємо такі рекурентні формули:

$$
\begin{aligned}
& Æ_{i}^{-}(k+1)=\xi_{i}^{-}(k)+\delta_{i}^{-}(k+1), \\
& \xi_{i}^{+}(k+1)=\xi_{i}^{+}(k)-\delta_{i}^{+}(k+1), i=1, \ldots, m,
\end{aligned}
$$

де $Æ_{i}^{-}(k+1)$ та $£_{i}^{+}(k+1)$ - нижнє та верхнє значення $i$ - тої вихідної $y_{i}$ характеристики системи для фіксованого вектора входів $\vec{x}_{i}$ на $k+1$-й ітерації локалізаційного методу; $\delta_{i}^{-}(k+1), \delta_{i}^{+}(k+1)$ - величини, значення яких на кожній ітерації знаходяться за методикою, описаною в праці [6].

Шляхом проведення $k$-того спостереження у точках на кожній ітерації поступово уточнюємо інтервальні моделі, тобто зменшуємо ширину інтервалів прогнозування . При цьому, на кожній ітерації формули (8) набувають рекурентного вигляду 


$$
\begin{aligned}
& \delta y_{i}^{-}(k)=y_{i}^{-}-\xi_{i}^{-}(k), \\
& \delta y_{i}^{+}(k)=y_{i}^{+}-\xi_{i}^{+}(k), i=1, \ldots, N .
\end{aligned}
$$

Підставляючи значення $\delta y_{i}^{-}(k), \delta y_{i}^{+}(k) 3$ формули (11) у вектори $\delta \vec{Y}^{-}, \delta \vec{Y}^{+}$, а останні у формулу (7) та з врахуванням теореми 1, 3 праці [4] отримаємо рекурентну формулу допустимої області у вигляді багатомірного еліпсоїда:

$\left.Q_{m}^{-}(k+1)=\left\{\delta \vec{b} \in R^{m} \mid(\delta \vec{b}-\delta \overrightarrow{\vec{b}}(k+1))^{T} \cdot \widetilde{F}^{T} \cdot \widetilde{E}^{-2}(k+1) \cdot \widetilde{F} \cdot(\delta \vec{b}-\delta \overrightarrow{\vec{b}}(k+1)) \leq 1\right\}\right\}$

де $\overrightarrow{\vec{b}}(k+1)$ - вектор, який задає центр ваги допустимого еліпсоїда на $k$ - тій ітерації і визначається за формулою

$$
\begin{aligned}
& \overrightarrow{\bar{b}}(k+1)=\widetilde{F}^{-1} \cdot 0,5 \cdot \\
& \left(\left(\delta y_{1}^{+}(k+1)+\delta y_{1}^{-}(k+1)\right), \ldots,\right. \\
& \left(\delta y_{i}^{+}(k+1)+\delta y_{i}^{-}(k+1)\right), \ldots, \\
& \left.\left.\delta y_{m}^{+}(k+1)+\delta y_{m}^{-}(k+1)\right)\right)^{T} ;(13) \\
& \widetilde{E}(k+1) \text { - діагональна матриця допусків, }
\end{aligned}
$$
відхилень вихідних характеристик, отриманих на $k$ - тій ітерації

$$
\begin{aligned}
& \widetilde{E}(k+1)=\operatorname{diag}\{0,5 . \\
& \left(\delta y_{1}^{+}(k+1)-\delta y_{1}^{-}(k+1)\right), \ldots \\
& \left(\delta y_{i}^{+}(k+1)-\delta y_{i}^{-}(k+1)\right), \ldots, \\
& \left.\left(\delta y_{m}^{+}(k+1)-\delta y_{m}^{-}(k+1)\right)\right) .
\end{aligned}
$$

Зауважимо, що кожне спостереження, якщо воно єінформативним, проведене у точці може одночасно звузити частину, або усі інтервали , У просторі параметрів це означає переміщення декількох не паралельних граней області локалізації в сторону зменшення іï розмірів. Такий випадок зображено у просторі параметрів на рис. 1 для $m=2$.

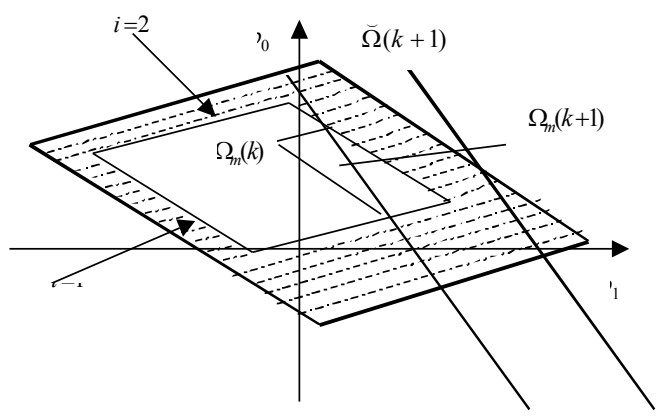

Рис. 1. Ілюстрація сумішеення процеедур локалізації та допустимого оцінювання.
Штрих - пунктирними лініями виділена область, 3 якої побудована допустима область $\widetilde{\Omega}_{m}$, що отримана на $k$ - тій ітерації локалізаційного методу. На рис. 2 зображена область $\widetilde{\Omega}_{m}$ та її допустима оцінка у вигляді еліпса.

Як видно з рис. 1 та рис. 2, розміри допустимої області тим більші чим менші розміри області локалізації, тобто чим точніші інтервальні моделі. Очевидно, що найбільших допусків можна отримати, коли відомі номінальні (“точні”) значення $\vec{b}_{0}=\left(b_{01}, . ., b_{0 m}\right)^{T}$ параметрів моделі. Результати чисельних експериментів, проведені із застосуванням локалізаційного методу показали, що при збільшенні кількості спостережень розміри локалізаційної області зменшуються, але одночасно зростає частка неінформативних спостережень.

Оскільки запропонований підхід допустимого оцінювання базується на локалізаційному методі, то для його практичної реалізації необхідно задати умову зупинки обчислювальної процедури при досягненні певної допустимої області. Наприклад, ця умова може бути задана так: $V_{\widetilde{\Omega}_{m}}^{0} \geq V_{\widetilde{\Omega}_{m}}(k+1)$, де $V_{\widetilde{\Omega}_{m}}^{0}$ заданий об’єм допустимої області, а $V_{\widetilde{\Omega}_{m}}(k+1)$ - розрахований на $k+1$ ітерації за допомогою формули

$V_{\widetilde{\Omega}_{m}}(k+1)=\sqrt{\prod_{i=1}^{m}\left(\delta y_{i}^{+}(k+1)-\delta y_{i}^{-}(k+1)\right)^{2} \cdot \operatorname{det}\left(\widetilde{F} \cdot \widetilde{F}^{T}\right)^{-1}}$.

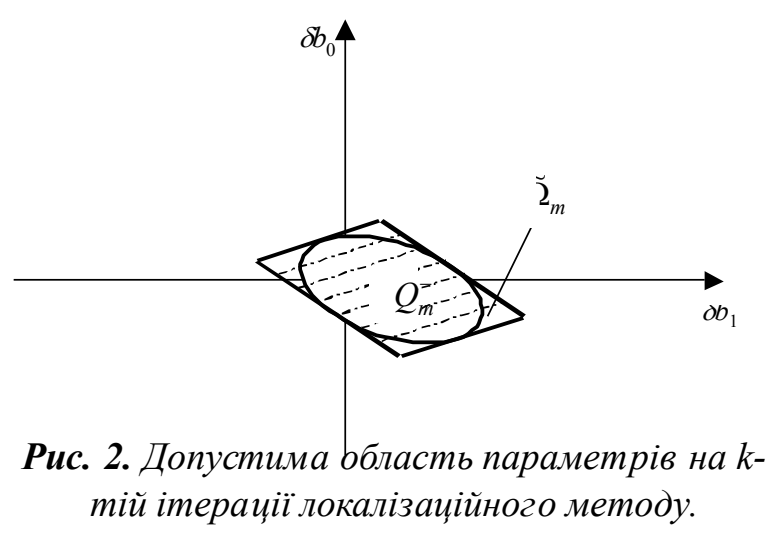

Допустиме оцінювання параметрів лінеаризованої інтервальної моделі в умовах ідентифікації базових функцій.

Розглянемо випадок, коли вихідні змінні $y_{i}$ 
системи нелінійно залежать від іï входів $\vec{x}$ та параметрів $\vec{b}$

$$
y_{i}(\vec{x}, \vec{b})=g_{i}\left(\sum_{j=1}^{m} \varphi_{i j}\left(\vec{x}, \vec{a}_{j}\right) \cdot \vec{b}\right), i=1, \ldots, N
$$

де $\varphi_{i j}\left(\vec{x}, \vec{a}_{j}\right) \quad(j=1, \ldots, m)-$ базові функції відомого вигляду з невідомими векторами $\vec{a}_{j}$ параметрів, які надалі називатимемо коефіцієнтами.

Припустимо, що ідентифікація невідомих векторів $\vec{a}_{j}$ коефіцієнтів здійснюється в результаті незалежних серій спостережень в точках $\vec{x}_{k}(k=1, \ldots, K)$, коли результати спостережень задаються в інтервальному вигляді, тобто

$$
\begin{array}{cc}
\vec{x}_{k},\left[\varphi_{i j}^{-}\left(\vec{x}_{k}, \vec{a}_{j}\right) ; \varphi_{i j}^{+}\left(\vec{x}_{k}, \vec{a}_{j}\right)\right], & i=1, \ldots, N, \\
j=1, \ldots, m, k=1, \ldots, K, & (17) \\
\text { де }\left[\varphi_{i j}^{-}\left(\vec{x}_{k}, \vec{a}_{j}\right) ; \varphi_{i j}^{+}\left(\vec{x}_{k}, \vec{a}_{j}\right)\right]-\text { інтервали }
\end{array}
$$
можливих значень функцій $\varphi_{i j}\left(\vec{x}, \vec{a}_{j}\right)$ $(j=1, \ldots, m)$ в точках $\vec{x}_{k}$. В результаті застосування методу аналізу інтервальних даних, отримаємо області можливих значень векторів $\vec{a}_{j}$ і відповідні до них функціональні коридори

$$
\begin{aligned}
& {\left[\phi_{i j}(\vec{x})\right]=\left[\phi_{i j}^{-}(\vec{x}) ; \oint_{i j}^{+}(\vec{x})\right], i=1, \ldots, N,} \\
& j=1, \ldots, m .
\end{aligned}
$$

3 урахуванням цих функціональних коридорів, оцінки нелінійних залежностей (16) матимуть інтервальний вигляд

$$
\left[\xi_{i}(\vec{x}, \vec{b})\right]=g_{i}\left(\sum_{j=1}^{m}\left[\phi_{i j}(\vec{x})\right] \cdot \vec{b}\right), i=1, \ldots, N
$$

Нехай із фізичних міркувань відомий деякий номінальний вектор параметрів $\vec{b}_{0}=\left(b_{01}, . ., b_{0 m}\right)^{T}$, що при фіксованому наборі входів $\vec{x}_{k}$ забезпечує номінальні інтервали виходів [ $\left.€_{0 i}\right]=\left[€_{i}\left(\vec{x}_{k}, \vec{b}_{0}\right)\right]$. Лінеаризуємо залежності (19), застосуванням розкладу в ряд Тейлора в околі вектора номінальних значень параметрів $\vec{b}_{0}$

$$
\begin{aligned}
& {\left[£_{i}\left(\vec{x}_{k}, \vec{b}\right)\right]=\left[£_{0 i}\right]+\sum_{j=1}^{m}\left[\S_{i j}^{k}\right] \cdot \delta b_{j},} \\
& i=1, \ldots, N, \\
& \text { де; }
\end{aligned}
$$

$$
\left[\oint_{i j}^{k}\right]=\left.\frac{\partial g_{i}\left(\sum_{j=1}^{m}\left[\oint_{i j}\left(\vec{x}_{k}\right)\right] \cdot b_{j}\right)}{\partial b_{j}}\right|_{\vec{b}=\vec{b}_{0 j}} \cdot(i=1, \ldots, N)
$$

Тепер задамо допустимі, 3 точки зору функціональної придатності статичної системи, інтервали виходів $\left[y_{i}^{-}, y_{i}^{+}\right]$. Спираючись на твердження 1 , отримаємо умови забезпечення функціональної придатності системи

$$
\left[€_{i}\left(\vec{x}_{k}, \vec{b}\right)\right] \subseteq\left[y_{i}^{-}, y_{i}^{+}\right], \forall i=1, \ldots, N .
$$

Перепишемо ці умови з урахуванням заміни інтервалів $\left[f_{i}\left(\vec{x}_{k}, \vec{b}\right)\right](i=1, \ldots, N)$, на інтервали, обчислені з виразів (20) і користуючись властивостями інтервальних включень [4]:

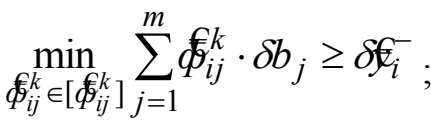

$$
\begin{aligned}
& \max _{\Phi_{i j}^{k} \in\left[\Phi_{i j}^{k}\right]} \sum_{j=1}^{m} \Phi_{i j}^{k} \cdot \delta b_{j} \leq \delta £_{i}^{+}, \quad i=1, \ldots, N
\end{aligned}
$$

де $\delta £_{i}^{-}=y_{i}^{-}-£_{0 i}^{-} ; \delta £_{i}^{+}=y_{i}^{+}-£_{0 i}^{+}$.

Як і раніше, будемо вважати, що $N=m$. В загальному випадку розв'язком системи нерівностей (22) при $N=m \in$ об'єднана множина $\widetilde{\Omega}_{0 m}$ допустимих відхилень параметрів $\delta b_{j}$ від номінальних значень. У просторі параметрів отриманий розв'язок $\epsilon$ не опуклим многогранником, що суттєво ускладнює знаходження його допустимої еліпсоїдальної оцінки. Як видно із системи (22), при звуженні інтервалів [ $\left.\varlimsup_{i j}^{k}\right]$ ( $i=1, \ldots, m, j=1, \ldots, m)$ до точкових значень вона стає еквівалентною ІСЛАУ (2), для розв'язку якої існує єдина оптимальна допустима оцінка у вигляді багатомірного еліпсоїда.

Отже, чим менша ширина інтервалів [ $\left.\bar{\emptyset}_{i j}^{k}\right]$ ( $i=1, \ldots, m, j=1, \ldots, m)$, тим точнішу еліпсоїдальну оцінку допустимої області розв'язку системи нерівностей (22) можна отримати. 
Наявність інтервалів

$$
\left[\bar{\phi}_{i j}^{k}\right](i=1, \ldots, m, j=1, \ldots, m)
$$

у системі нерівностей (22) призводить до існування множини можливих $m$ - вимірних еліпсоїдів, вписаних у допустиму область $\widetilde{\Omega}_{0 m}$. Для опису цієї множини складемо таку систему нерівностей:

$$
\begin{aligned}
& \sum_{j=1}^{m} \S_{i j}^{k} \cdot \delta b_{j} \geq \delta £_{i}^{-} ; \sum_{j=1}^{m} \varlimsup_{i j}^{k} \cdot \delta b_{j} \leq \delta £_{i}^{+}, \\
& i=1, \ldots, N=m,
\end{aligned}
$$

де $\bar{\Phi}_{i j}^{k}$ - будь-які значення, вибрані із відповідних інтервалів $\left[\bar{\Phi}_{i j}^{k}\right](i=1, \ldots, m$, $j=1, \ldots, m)$. Позначимо за $\widetilde{F}_{k}=\left\{\Phi_{i j}^{k}\right.$, $i=1, \ldots, m, j=1, \ldots, m\}-$ матрицю розмірності $(m \times m),\left[\widetilde{F}_{k}\right]=\left\{\left[\mathscr{q}_{i j}^{k}\right], i=1, \ldots, m, j=1, \ldots, m\right\}-$ матрицю розмірності $(m \times m)$ з інтервальними компонентами, а за

$$
\delta Y^{€-}=\left\{\delta E_{i}^{-}, i=1, \ldots, m\right\}, \delta Y^{E^{+}}=\left\{\delta €_{i}^{+}, i=1, \ldots, m\right\}
$$

вектори, складені із верхніх та нижніх меж інтервалів [ $\left.\delta £_{i}^{-}, \delta £_{i}^{+}\right] .3$ урахуванням уведених позначень отриману систему можна переписати у матричному вигляді

$$
\delta Y^{€} \leq \widetilde{F}_{k} \cdot \delta \vec{b} \leq \delta Y^{E}
$$

Нехай $\widetilde{\Omega}_{m}\left(\widetilde{F}_{k}\right)$ - розв'язок системи (24) при фіксованому наборі $\oint_{i j}^{k} \quad(i=1, \ldots, m$, $j=1, \ldots, m)$. Тоді, в силу лінійності систем (23), (24), справедливим є включення

$$
\widetilde{\Omega}_{m}\left(\widetilde{F}_{k}\right) \subseteq \widetilde{\Omega}_{0 m}, \forall \widetilde{F}_{k} \in\left[\widetilde{F}_{k}\right],
$$

3 якого витікає, що розв'язок системи нерівностей (24) є допустимою оцінкою розв' язку системи нерівностей (23).

Зауважимо, що включення $\widetilde{F}_{k} \in\left[\widetilde{F}_{k}\right]$ означає, що кожна компонента матриці $\widetilde{F}_{k}$ належить відповідному інтервалу - компоненті інтервальної матриці [ $\left.\widetilde{F}_{k}\right]$.

Користуючись виразом для оптимальної еліпсоїдальної оцінки (4), множину допустимих еліпсоїдальних оцінок запишемо у такому вигляді:

$Q_{m}^{-}\left(\widetilde{F}_{k}\right)=\left\{\delta \vec{b} \in R^{m} \mid(\delta \vec{b}-\delta \overrightarrow{\bar{b}})^{T} \cdot \widetilde{F}_{k}{ }^{T} \cdot \widetilde{E}^{-2} \cdot \widetilde{F}_{k} \cdot(\delta \vec{b}-\delta \overrightarrow{\bar{b}}) \leq 1\right\}$

$\widetilde{F}_{k} \in\left[\widetilde{F}_{k}\right]$

де $\delta \overrightarrow{\bar{b}}=\widetilde{F}_{k}^{-1} \cdot \delta \stackrel{€}{\delta} ; \widetilde{E}$ - діагональна матриця допусків $0,5 \cdot\left(\delta €_{i}^{+}-\delta £_{i}^{-}\right), i=1, \ldots, m$ відхилень вихідних характеристик статичної системи; $\delta \stackrel{€}{E}=\left(\delta \bar{F}_{1}, \ldots, \delta \bar{E}_{i}, \ldots, \delta \bar{E}_{m}\right)^{T}$ - век тор 3 компонентами $\delta \bar{\xi}_{i}=0,5 \cdot\left(\delta \S_{i}^{+}+\delta £_{i}^{-}\right)$.

На рис. 3 для випадку $m=2$ схематично зображені: область $\widetilde{\Omega}_{0 m}$; іï допустима оцінка $\widetilde{\Omega}_{m}\left(\widetilde{F}_{k}\right)$, обчислена для матриці $\widetilde{F}_{k}$, компонентами якої є середини інтервалів [ $\left.\bar{\Phi}_{i j}^{k}\right]$ $(i=1, \ldots, 2, j=1, \ldots, 2)$; допустима оцінка у вигляді еліпса

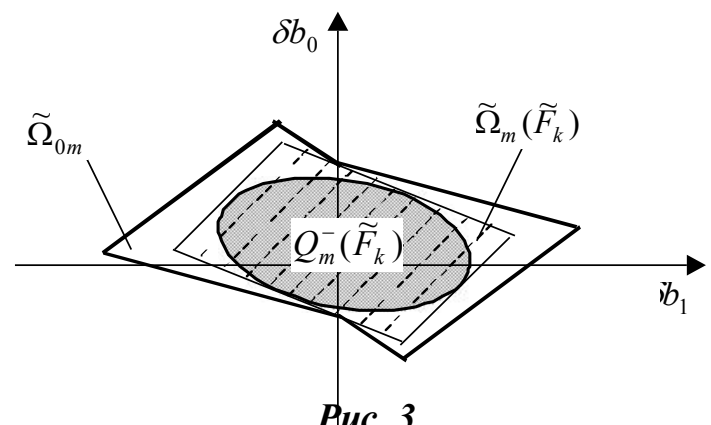

Як видно $з$ рисунка, отримані допустимі оцінки є неоптимальними, оскільки не забезпечують максимального “покриття” області $\widetilde{\Omega}_{0 \mathrm{~m}}$. Очевидним також є те, що оптимальна допустима оцінка даної області існує і залежить від вибору матриці $\widetilde{F}_{k} \in\left[\widetilde{F}_{k}\right]$, а іi знаходження може бути формалізоване у вигляді такої задачі математичного програмування 3 нелінійною цільовою функцією:

$$
V\left(Q_{m}^{-}\left(\widetilde{F}_{k}\right)\right) \stackrel{\widetilde{F}_{k}}{\longrightarrow} \max , \widetilde{F}_{k} \in[]
$$

де $V\left(Q_{m}^{-}\left(\widetilde{F}_{k}\right)\right)$ - об'єм допустимого багатомірного еліпсоїда.

В загальному випадку процедури знаходження розв'язку задачі (27) є достатньо складними. Тому в даних умовах найбільш обгрунтованим буде підхід, коли конфігурація допустимого еліпсоїда, визначається не із 
розв'язку задачі (27), а вибирається виходячи iз умови його максимальної подібності до технологічного еліпсоїда розсіювання випадкових значень параметрів. Очевидно, що саме у цьому випадку буде забезпечуватися максимальна точність та працездатність статичної системи. Якщо ж область розсіювання параметрів $\epsilon$ невідомою, то у випадку незначної розмірно сті задачі (27), за допустиму еліпсоїдальну оцінку можна вибрати найкращу (найбільшого об’єму) серед отриманих для матриць $\widetilde{F}_{k}$, компонентами яких є комбінації меж інтервалів [ $\left.\bar{\Phi}_{i j}^{k}\right](i=1, \ldots, m, j=1, \ldots, m)$. Коли ж значення $m \epsilon$ достатньо велике $\mathrm{i}$ застосування методів повного перебору стає не можливим, то допустиму оцінку можна отримати на основі матриці $\widetilde{F}_{k}$, компонентами якої $\epsilon$ середини інтервалів [ $\left.\oint_{i j}^{k}\right](i=1, \ldots, 2$, $j=1, \ldots, 2)$, як це показано на рис. 3 .

\section{ВИСНОВКИ}

Розглянуто методи побудови допустимих еліпсоїдальних оцінок області працездатності статичної системи за умов іï опису інтервальними моделями. Доведено твердження стосовно умов існування області допусків, коли статична система описується інтервальною моделлю i розроблено ітераційний алгоритм, який дозволяє сумістити процедури локалізації області параметрів моделі і допустимого еліпсоӥдального оцінювання і тим самим оптимізувати витрати на проведення експерименту для досягнення заданої допустимої області параметрів. Формалізовано і проведено аналіз задачі допустимого оцінювання пара- метрів лінеаризованої інтервальної моделі в умовах ідентифікації базових функцій, який дозволив виробити підходи до вибору конфігурації допустимої еліпсоїдальної оцінки.

\section{ЛІТЕРАТУРА}

1. Дивак М.П, Стахів П.Г. Ідентифікачія моделей об'єктів в умовах інтервальної невизначеності на основі методів аналізу інтервальних даних // АВТОМАТИКА-2000. Праці МК з управління, Львів 11-15 вересня 2000: Праці в 7-ми томах.-T. 2. - Львів: Державний НДІ інформаційної інфраструктури, 2000.-С. 90-97.

2. Дивак М.П. Оиінка точності характеристик радіоелектронних кіл методами аналізу інтервальних даних // Праці Ін-ту електродинаміки НАНУ. Електротехніка'2001: 3б. наукових праць.-К: ІЕД НАН України, 2001.C.29-33.

3. Кривошейкин А.В. Точность параметров и настройка аналогов blх радиоелектронных uеeneй. М., 1983. $136 \mathrm{c}$.

4. Дивак М.П. Франко Ю.П. Методи аналізу інтервальних даних стосовно оцінки технологічних прочесів виготовлення інтегральних схем // Теоретична електротехніка. -2000. №55.- C. 167-173.

5. Дивак М.П. Метод локалізаиії гарантованих очінок в задачах параметричної ідентифікаиіі // Вимірювальна та обчислювальна техніка в технологічних прочесах. 2000. - №4. - C. 12-17.

6. Дивак М.П., Стахів П.Г. Реалізація методу локалізацї параметрів інтервальних моделей з виділенням насиченого блоку експерименту на паралельних обчислювальних графах. //Электроника и связь. - 2001. №12. C. $120-124$.

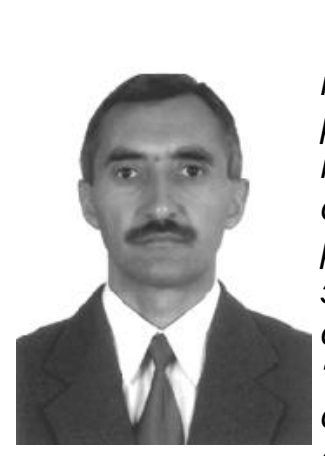

Дивак Микола Петрович народився 1964 року. В 1986 році закінчив Львівський політехнічний інституm $i$ отримав кваліфікацію радіоінженера. В 1992 році захистив кандидатську дисертацію на тему "Розробка методів оптимального планування експерименту i аналізу інтервальних даних". В 1999 році вступив до докторантури Тернопільської академії народного господарства і підготував до захисту дисертацію на здобуття вченого ступеня доктора технічних наук на тему
“Теоретичні засади побудови моделей "вхідвихід" статичних систем методами аналізу інтервальних даних". Опублікував понад 60 наукових та методичних праць. На даний час працює завідувачем кафедри комп'ютерних наук інституту комп'ютерних технологій Тернопільської академії народного господарства.

Область наукових інтересів: розробка та застосування методів множинного оиінювання та інтервального аналізу для моделювання статичних і динамічних систем в сорері економіки, екології та технологічних галузях. 